\title{
New aspects in pathogenesis of konzo: neural cell damage directly caused by linamarin contained in cassava (Manihot esculenta Crantz)
}

\author{
V. G. Sreeja, N. Nagahara*, Q. Li and M. Minami \\ Department of Environmental Medicine, Nippon Medical School, 1-1-5, Sendagi, Bunkyo-ku, Tokyo 113-8602, \\ Japan
}

(Received 4 October 2002 - Revised 3 February 2003 - Accepted 22 March 2003)

Epidemic spastic paraparesis (konzo) found in tropical and subtropical countries is known to be caused by long-term intake of cassava (Manihot esculenta Crantz), which contains a cyanoglucoside linamarin ( $\alpha$-hydroxyisobutyronitrile- $\beta$-D-glucopyranoside). It has been reported that linamarin is enzymatically converted to cyanide by bacteria in the intestine, and this is absorbed into the blood and then damages neural cells. However, unmetabolized linamarin was found in the urine after oral administration of cassava; thus, we hypothesized that konzo could be caused by direct toxicity of the unmetabolized linamarin that was transferred to the brain and could be transported into neural cells via a glucose transporter. In the present study it was confirmed that linamarin directly damaged neural culture pheochromocytoma cell (PC) 12 cells; 0.10 mM-linamarin caused cell death at 13.31 (SD 2.07) \%, which was significantly different from that of control group (3.18 (SD 0.92) \%, P=0.0004). Additional $10 \mu \mathrm{M}$-cytochalasin $\mathrm{B}$, an inhibitor of a glucose transporter, prevented cell death: the percentage of dead cells significantly decreased to 6.06 (SD 1.98), $P=0.0088$ ). Furthermore, glucose also prevented cell death. These present results strongly suggest that linamarin competes with cytochalasin B and glucose for binding to a glucose transporter and enters into cells via glucose transporter.

Cassava: Linamarin: Konzo: Glucose transporter

A root of cassava (Manihot esculenta Crantz) shrub is an important staple food to millions of people in tropical and subtropical countries. Lancaster et al. (1982) were the first to report that prolonged consumption of cassava caused a metabolic neurological disease, konzo. In the last decade, several epidemics of konzo have been reported among the rural populations in Africa, including Mozambique, Tanzania, Zaire and the Central African Republic (Howlett, 1990). The epidemiological studies suggest that the eating of cassava combined with malnutrition caused permanent damage to the nervous system (Howlett et al. 1990). The toxicity of cassava was caused by cyanogenic glucoside, linamarin ( $\alpha$-hydroxyisobutyronitrile- $\beta$-D-glucopyranoside) (Sunderesan et al. 1987), which is contained mainly in the root. When processing of cassava is not sufficient, linamarin is not completely removed and a portion of it remains.

The ingested linamarin is though to be hydrolysed to glucose and cyanohydrins in the intestinal tract; hydrogen cyanide is produced by a catalytic reaction of bacterial B-glucosidase in the intestine (Winkler, 1958). The cyanide is rapidly absorbed from the intestine into the blood. In clinical cases, concentrations of cyanide in the blood of patients suffering from konzo were between 4 and
$70 \mu \mathrm{mol} / \mathrm{l}$ (Tylleskar et al. 1992), but the greater part of cyanide can be metabolized to much less toxic thiocyanate, since there are defending enzymes against cyanide, such as rhodanese or mercaptopyruvate sulfurtransferase, in the tissues of the whole body (Sylverster \& Sander, 1990; Nagahara et al. 1998) and the intravenous cyanide is eliminated at the rate of $17 \mu \mathrm{g} / \mathrm{kg}$ body weight per min (Macnamara, unpublished results).

It was also reported that after cassava porridge containing linamarin was eaten, about $25 \%$ linamarin was excreted in the urine within $24 \mathrm{~h}$ in unmetabolized form, and about $50 \%$ as the less-toxic thiocyanate (Barrett et al. 1977; Brimer \& Rosling, 1993; Carlsson et al. 1995, 1999; Hernandez et al. 1995); cyanide produced by hydrolysis of linamarin in the gut was absorbed into the blood and was systemically metabolized to thiocyanate (Maduagwu, 1989).

As linamarin contains a glucose moiety, linamarin could bind to a glucose transporter (GLUT), be carried through the blood-brain barrier and then transported into cells via GLUT; furthermore, neural cells take up and consume glucose much more than the other cells. Thus, we hypothesized that after linamarin was absorbed from the intestine into the blood and transferred to the brain, linamarin could 
be transported to the cytoplasm of neural cells via GLUT and then accumulated linamarin could degenerate the cells.

The purpose of the present study was to test this hypothesis. First, comparative studies on toxicity of linamarin and cyanide to hepatoma (Hepa) 1 cells and neural pheochromocytoma (PC) 12 cells were done; second, the effect of cytochalasin B, an endofacial inhibitor of GLUT, and/or glucose on toxicity of linamarin to PC12 cells was investigated. The results of the present study strongly suggest that linamarin binds to GLUT and can be transported into cytoplasm via GLUT.

\section{Materials and methods}

Roswell Park Memorial Institute medium 1640 (Nissui Pharmaceuticals, Tokyo, Japan), Dulbecco's modified Eagle's medium and fetal bovine serum (GIBCO BRL; Rockville, MD, USA), glucose (Wako Pure Chemicals Ltd, Osaka, Japan), linamarin (Toronto Research Chemicals Inc., North York, Canada) and cytochalasin B (ICN Pharmaceuticals Inc., Costa Mesa, CA, USA) were purchased.

Rat PC12 cell line was the kind gift of Dr K. Watabe, Department of Molecular Neuropathology, Tokyo Pharmacuticals Institute for Neuroscience, Japan. Mouse Hepal cell line was kindly given by Professor Y. Fujii, University of Tsukuba, Centre for Tsukuba Advanced Research Alliance, Japan.

\section{Cell culture}

PC12 cells were cultured in Roswell Park Memorial Institute medium 1640 containing fetal bovine seum $(100 \mathrm{ml} / \mathrm{l})$, glutamine $(0.3 \mathrm{mg} / \mathrm{ml})$ and gentamycine $(20 \mu \mathrm{g} / \mathrm{ml})$ in $50 \mathrm{ml}$ tissue-culture flasks coated with collagen (collagen $(100 \mathrm{~g} / \mathrm{l})$ in methanol $(300 \mathrm{ml} / \mathrm{l}))$. Hepa1 cells were cultured in Dulbecco's modified Eagle's medium containing fetal bovine serum $(100 \mathrm{ml} / \mathrm{l})$ and kanamycin $(60 \mu \mathrm{g} / \mathrm{ml})$. Cultures were maintained at $37^{\circ} \mathrm{C}$ in humidified $5 \% \mathrm{CO}_{2}$.

\section{Toxicity of linamarin and potassium cyanide for neural} (pheochromocytoma 12) and hepatic (hepatoma 1) cells

PC12 and Hepal cells $\left(2 \times 10^{5}\right.$ and $3 \times 10^{4}$ cells $/ \mathrm{ml}$ respectively) were incubated with different concentrations of linamarin (about $0.01-5.00 \mathrm{~mm}$ ) or potassium cyanide (about $0.001-0.250 \mathrm{~mm}$ ) in twenty-four well plates for $48 \mathrm{~h}$ at $37^{\circ} \mathrm{C}$ in $5 \% \mathrm{CO}_{2}$. Control experiment was also done without addition of linamarin and potassium cyanide. After incubation the cells were harvested and cell viability was determined by staining with Trypan Blue. Cell death $(\%)$ was calculated as dead cells $(n)$ per cells counted $(n)$.

\section{Effects of concentration of cytochalasin B on toxicity of linamarin to pheochromocytoma 12 cells}

PC1 2 cells $\left(2 \times 10^{5}\right.$ cells $\left./ \mathrm{ml}\right)$ were incubated with different concentrations of linamarin (about 0.01-5.00 mM) and $10 \mu \mathrm{M}$-cytochalasin $\mathrm{B}$, a glucose transport inhibitor, in twenty-four well plates for $48 \mathrm{~h}$ at $37^{\circ} \mathrm{C}$ in $5 \% \mathrm{CO}_{2}$ (cytochalasin B did not show toxic effect on PC12 cells at $10 \mu \mathrm{M})$. In this experiment, $11 \mathrm{~mm}$-glucose was contained in the medium (commercial concentration of Roswell Park Memorial Institute medium). For a control group, PC12 cells were incubated in the medium containing no linamarin and cytochalasin B. As an experimental group, PC12 cells $\left(2 \times 10^{5}\right.$ cells $\left./ \mathrm{ml}\right)$ were incubated with $0 \cdot 001$, $0.010,0.100,0.250$ and $0.500 \mathrm{~mm}$-linamarin.

After incubation the cells were harvested and cell viability was determined by staining with Trypan Blue. Cell death $(\%)$ was calculated as dead cells $(n)$ per cells counted $(n)$.

\section{Effects of concentration of glucose with or without cytochalasin $B$ on toxicity of linamarin to pheochromocytoma 12 cells}

To investigate a competitively protective effect of glucose on transport of linamarin into cells, PC12 cells $\left(2 \times 10^{5}\right.$ cells $/ \mathrm{ml}$ ) were incubated for $48 \mathrm{~h}$ at $37^{\circ} \mathrm{C}$ in $5 \% \mathrm{CO}_{2}$ in medium containing 11 (commercial concentration), 15, 21,26 or $43 \mathrm{~mm}$-glucose for a control group, 11, 15, 21, 26 or $43 \mathrm{~mm}$-glucose with $0 \cdot 10 \mathrm{~mm}$-linamarin for an experimental group, and $11,15,21,26$ or $43 \mathrm{~mm}$-glucose with $0.10 \mathrm{~mm}$-linamarin and $10 \mu \mathrm{M}$-cytochalasin $\mathrm{B}$ for another experimental group.

After incubation the cells were harvested and cell viability was determined by staining with Trypan Blue. Cell death $(\%)$ was calculated as dead cells $(n)$ per cells counted $(n)$.

\section{Study on metabolism of linamarin in the cell}

To test whether linamarin serves as a substrate or an inhibitor of yeast hexokinase (Roche Diagnostics, Basel, Switzerland), a key enzyme of glycolysis, or whether linamarin is catalysed by rat recombinant rhodanese (Nagahara et al. 1995) or rat recombinant mercaptopyruvate sulfurtransferase (Nagahara \& Nishino, 1996) (cyanide metabolizing enzyme; Nagahara et al. 1999), linamarin was added $(0.50-2.00 \mathrm{mM})$ in each assay system for hexokinase (Harrison \& Gray, 1972), rhodanese (Sörbo, 1953) and mercaptopyruvate sulfurtransferase (Nagahara $\&$ Nishino, 1996) and kinetic studies were carried out.

\section{Statistical analysis}

All values were expressed as mean values and standard deviations. The significance of difference between values was estimated by Student's $t$ test and two-way ANOVA.

\section{Results \\ Comparison of toxicity of linamarin and cyanide for pheochromocytoma 12 and hepatoma 1 cells}

As shown in Fig. 1(a), 32.27 (SD 6.54) \% (n 3) PC12 cells were dead at 2.0 mM-linamarin; on the other hand, 35.58 (SD 3.54) \% (n 3) Hepa1 cells were dead at 5.0 mM-linamarin (Fig. 1(b)). Two-way ANOVA to compare values in two groups exposed to linamarin at $0.01,0.10,1.00$ and 2.00 (for PC12) or $2.50 \mathrm{~mm}$ (for Hepa1) represented significant difference $(P=0 \cdot 0000018)$. These results 

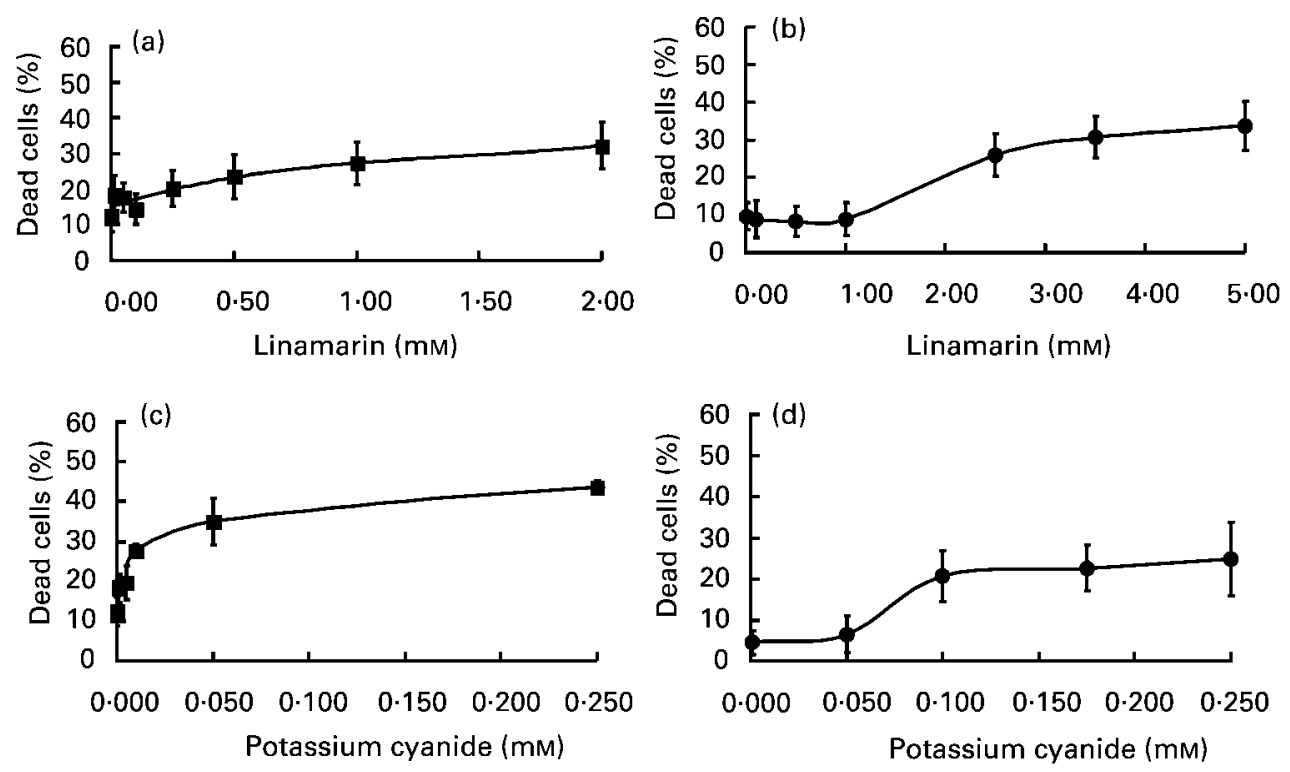

Fig. 1. Toxicity of linamarin and cyanide to pheochromocytoma (PC) 12 and hepatoma (Hepa)1 cells. (a), Linamarin toxicity to PC12 cells: PC12 cells at $2 \times 10^{5}$ cells $/ \mathrm{ml}$ were incubated with $0.01,0.05,0.10,0.25,0.50$ and $2.00 \mathrm{~mm}$-linamarin; (b), linamarin toxicity to Hepa1 cells: Hepa1 cells at $3 \times 10^{4}$ cells $/ \mathrm{ml}$ were incubated with $0.10,1.00,2.50$ and $5.00 \mathrm{~mm}$ linamarin; (c), cyanide toxicity to PC12 cells: PC12 cells at $2 \times 10^{5}$ cells $/ \mathrm{ml}$ were incubated with $0.001,0.005,0.010,0.050$ and $0.250 \mathrm{~mm}$-potassium cyanide; (d), cyanide toxicity to Hepa1 cells: Hepa1 cells at $3 \times 10^{4} \mathrm{cells} / \mathrm{ml}$ were incubated with $0.050,0.100$ and $0.250 \mathrm{~mm}$-potassium cyanide. For details of procedures, see p. 468 . Values are means with standard deviations shown by vertical bars $(n 3)$.

suggest that linamarin damages both PC12 and Hepa1 cells and PC12 cells are more sensitive to linamarin than Hepa1 cells.

As for a toxicity of cyanide, at $0.01 \mathrm{~mm}$-potassium cyanide 25.40 (SD 1.44) \% (n 3) PC12 cells were dead (Fig. 1(c); on the other hand, at $0.25 \mathrm{~mm} 24.84$ (SD 8.93) $\%$ ( $n$ 3) of Hepal cells were dead (Fig. 1(d)). Two-way ANOVA to compare values in two groups exposed to cyanide at $0.001,0.050$ and $0.250 \mathrm{~mm}$ represented a significant difference $(P=0 \cdot 0062)$, suggesting that $\mathrm{PC} 12$ cells were more sensitive to cyanide than Hepal cells and that neural cells are more susceptible to cyanide than hepatic cells.

In comparing the toxic effect of linamarin with that of cyanide, at $0.50 \mathrm{~mm}$-linamarin 23.56 (SD 6.23) \% (n 3) PC12 cells were dead (Fig. 1(a)), whereas at $0.500 \mathrm{~mm}$-cyanide 46.86 (SD 1.79) \% ( $n$ 3) PC12 cells died (Fig. 1(c)). At 0.10 mm-linamarin, 8.89 (SD 2.31) \% (n 3) Hepa1 cells were dead (Fig. 1(b)), whereas at 0.100 mM-cyanide 20.67 (SD 6.23) \% (n 3) Hepa1 cells were dead (Fig. 1(d)). These findings suggest that cyanide is much more toxic to PC12 and Hepal cells than linamarin.

\section{Possible mechanism of toxicity of linamarin in pheochromocytoma 12 cells}

When cells were incubated with linamarin combined with $10 \mu \mathrm{M}$-cytochalasin $\mathrm{B}$, dead cells $(\%)$ were significantly decreased (Fig. 2); 0.001, 0.010, 0.100, 0.250 and $0.500 \mathrm{~mm}$-linamarin caused cell death of 4.22 (SD 2.43), 8.69 (SD 2.31), 15.67 (SD 2.75), 22.54 (SD 4.33) and 29.49 (SD 5.06) \%, respectively ( $n$ 5), whereas cytochalasin $\mathrm{B}$ protected for the cell death caused by linamarin, and dead cell $(\%)$ significantly decreased to 2.14 (SD 1.97), 4.22 (SD 2.07), 8.34 (SD 3.27), 13.41 (SD 3.87) and 17.47 (SD 5.46) ( $n$ 5). These values in two groups except values at $1.00 \mu \mathrm{M}$-linamarin were significantly different $(P=0.05$, $0.032,0.04$ and 0.039 , respectively). These findings indicate that the toxicity of linamarin to PC12 cells is partially protected by cytochalasin B.

On the other hand, as shown in Fig. 3, glucose also affected the mortality of PC12 cells, depending on the

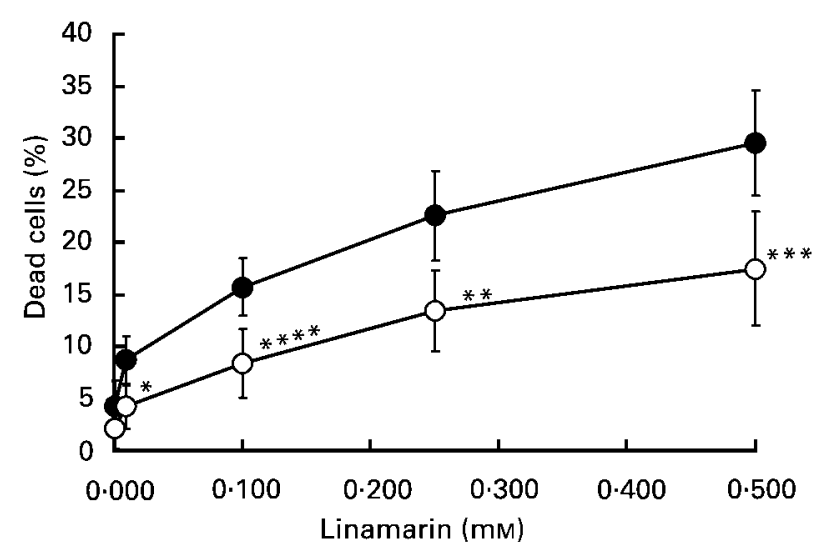

Fig. 2. Effect of cytochalasin $B$ on toxicity of linamarin to pheochromocytoma (PC) 12 cells. PC12 cells at $2 \times 10^{5}$ cells $/ \mathrm{ml}$ were incubated with $0.001,0.010,0.100,0.250$ and $0.500 \mathrm{~mm}$-linamarin alone (with $11 \mathrm{~mm}$-glucose contained in Roswell Park Memorial Institute medium) as a control group ( $\bullet$, and $10 \mu \mathrm{M}$-cytochalasin B added to each culture containing different concentration of linamarin as an experimental group (O). For details of procedures, see p. 468. Values are means with standard deviations shown by vertical bars $(n 5)$. Mean values were significantly different from that of control group: ${ }^{\star} P=0.05,{ }^{\star \star} P=0.04,{ }^{\star \star \star} P=0.037,{ }^{\star \star \star \star} P=0.032$. 
concentration, probably due to increase in osmolarity by glucose. When glucose concentration was $11 \mathrm{~mm}$ (the concentration of glucose in a commercial medium) without addition of linamarin and cytochalasin B, 2.58 (SD 0.44) $\%$ ( $n$ 5) cells were dead; 0.10 mM-linamarin (with $11 \mathrm{~mm}$-glucose) significantly increased cell death to 15.67 (SD 2.76) \% ( $n$ 5) $(P=0.00039)$, whereas $10 \mu \mathrm{M}$-cytochalasin B (with $11 \mathrm{~mm}$-glucose) protected the cell death and cell death (\%) significantly decreased to 8.34 (SD 3.27) ( $n$ 5) $(P=0.032)$, which was significantly different from that of a control group $(P=0.025)$.

When glucose concentration was $15 \mathrm{~mm}$ without addition of linamarin and cytochalasin B, 3.18 (SD 0.92) $\%(n$ 5) of cells were dead; 0.10 mM-linamarin (with $15 \mathrm{~mm}$-glucose) significantly increased cell death to $13 \cdot 31$ (SD 2.07) \% (n 5) $(P=0 \cdot 0004)$, whereas $10 \mu \mathrm{M}$-cytochalasin B (with $15 \mathrm{~mm}$-glucose) protected from cell death and dead cells significantly decreased to 6.06 (SD 1.98) \% (n 5) $(P=0.0088)$, which was not significantly different from that of a control group $(P=0.056)$. When glucose concentration was $21 \mathrm{mM}, 5 \cdot 17$ (SD 1.25) \% ( $n$ 5) of cells were dead in a control group; however, $0.10 \mathrm{~mm}$-linamarin (with $21 \mathrm{~mm}$ glucose) did not significantly increase cell death (6.09 (SD 2.72) \% (n 5) $(P=0.6)$, and cytochalasin $\mathrm{B}$ (with $21 \mathrm{~mm}$-glucose) also did not significantly decrease cell death $(5 \cdot 17$ (SD 1.25) \% ( $n$ 5) $(P=0 \cdot 68)$.

In comparing linamarin toxicity among groups in the medium containing different concentrations of glucose, there was no significant difference between groups in the medium containing $11 \mathrm{~mm}$ - and $15 \mathrm{~mm}$-glucose. On the other hand, $21 \mathrm{mM}$-glucose was more toxic to PC12 cells than $15 \mathrm{~mm}$-glucose, although the difference was not significant $(P=0 \cdot 11)$; however, linamarin toxicity was significantly reduced compared with the group treated with

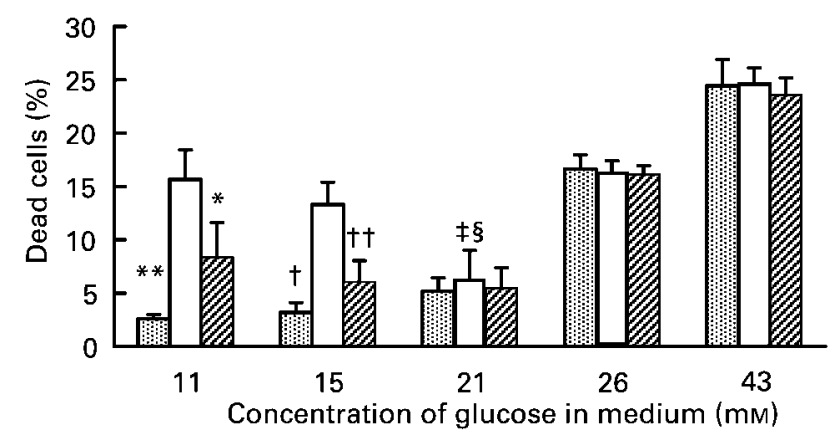

Fig. 3. Effect of glucose and/or cytochalasin B on toxicity of linamarin to pheochromocytoma (PC) 12 cells. PC12 cells at $2 \times 10^{5}$ cells $/ \mathrm{ml}$ were incubated in the medium containing 11,15 , 21,26 or $43 \mathrm{~mm}$-glucose alone as a control group (国), 11, 15, 21, 26 or $43 \mathrm{~mm}$-glucose with $0.10 \mathrm{~mm}$-linamarin ( $\square$ ), and 11, 15, 21, 26 or $43 \mathrm{~mm}$ with $0.10 \mathrm{~mm}$-linamarin and $10 \mu \mathrm{M}$-cytochalasin $\mathrm{B}(\mathbb{Q})$. For details of procedures, see p. 468. Values are means with standard deviations shown by vertical bars $(n 5)$. Mean values were significantly different from those of the group treated with linamarin in the medium containing $11 \mathrm{~mm}$-glucose: ${ }^{\star} P=0.032, \quad{ }^{\star \star} P=0.0039$. Mean values were significantly different from those of the group treated with linamarin in the medium containing $15 \mathrm{~mm}$-glucose: $\dagger P=0.00043, \dagger \dagger P=0.0088$. Mean values were significantly different from those of same treatment group in the medium containing $11 \mathrm{~mm}$-glucose: $\ddagger P=0 \cdot 01$. Mean values were significantly different from those of the same treatment group treated in the medium containing $15 \mathrm{~mm}$-glucose: $\S P=0.0011$.
$0 \cdot 1 \mathrm{~mm}$-linamarin in the medium containing $15 \mathrm{mM}$-glucose $(P=0 \cdot 01)$, suggest that glucose competes linamarin for GLUT. These findings conclude that cell damage by linamarin is protected not only by cytochalasin $\mathrm{B}$, but also by glucose.

\section{Effect of transported linamarin on metabolism in the cell}

Linamarin (about $0.50-2.00 \mathrm{~mm}$ ) did not inhibit hexokinase, a key enzyme in the first step of glycolysis, and hexokinase did not catalyse linamarin, suggesting that transported linamarin does not serve as a sugar source for glycolysis and reduce ATP production. Furthermore, rhodanese and mercaptopyruvate sulfurtransferase, cyanide detoxification enzymes, were not inhibited by linamarin, suggesting that transported linamarin did not inhibit detoxification of cyanide via transsulfuration.

\section{Discussion}

The results of the present study strongly suggest that linamarin could bind to GLUT and enter cells. Transported linamarin directly damages both neural PC12 and hepatic Hepa1 cells, which is consistent with the fact that neural cells consume glucose more than hepatic cells and hepatic cells contain more defence mechanisms, i.e. against cyanide than neural cells (Nagahara et al. 1999).

In the present study, we regarded cell death (\%) as dysfunction of the cells exposed to toxic reagents, as there is no suitable marker for cell dysfunction by different toxic reagents, linamarin and cyanide. It is proper that dose of the reagent needed to impair the cell function is much less than that to cause cell death.

Previous reports show that factors other than cyanide were responsible for histopathological changes observed in the liver of dogs fed gari (a cassava product) (Kamalu, 1991). On the other hand, in chronic cyanide poisoning, enlargement of the thyroid gland a distinctive finding, but this is not observed in konzo. It is possible that there is a change in normal flora in the intestine, resulting in reduction of the hydrolysis of linamarin contained in cassava for a long time (Kamalu, 1993), indicating that enzymatic conversion of linamarin to cyanide is reduced in gastrointestinal tract. However when cassava was orally administrated, unmetabolized linamarin was found in the urine (Barrett et al. 1977; Brimer \& Rosling, 1993; Carlsson et al. 1995, 1999; Hernandez et al. 1995); therefore, linamarin can be directly absorbed in the intestine.

There are no reports of the concentration of linamarin in the serum of patients suffering from konzo, but thiocyanate concentration has been reported: the mean value for three patients was about $300 \mu \mathrm{M}$ (Tylleskar et al. 1992). Moreover, contents of thiocyanate and linamarin excreted in $24 \mathrm{~h}$ urine collections after oral administration of cassava were reported as being present in a 2:1 ratio (Carlsson et al. 1999). Based on these results, in spite of the difference in metabolism and renal clearance between thiocyanate and linamarin, it is estimated that concentration of linamarin in the patient's serum was $>150 \mu \mathrm{M}$. Linamarin at this concentration in a medium caused $15 \%$ cell death in PC12. We consider that chronic exposure of linamarin at 
this concentration would damage to neural cells in vivo. In cyanide poisoning, lethal concentration of cyanide in blood is $>90 \mu \mathrm{M}$ in man (Ellenhorn, 1997). Cyanide at this concentration does not cause histological change in the brain in vivo, but causes about $40 \%$ cell death in PC12. Thus, there is a discrepancy between in vivo and in vitro results.

When PC12 cells were incubated with cytochalasin B and linamarin, the proportion of dead cells (\%) significantly decreased, suggesting that cytochalasin B prevented linamarin from entering the cells and consequently reduced the toxicity of linamarin. In fact, cytochalasin B binds specifically to a GLUT and inhibits uptake of 2-deoxyglucose, a glucose analogue (Bloch, 1973). Furthermore, it was found that glucose uptake was inhibited by low concentration of cytochalasin B (Stahl et al. 1989). In the brain, glucose is taken up from blood across the blood-brain barrier via GLUT1 (Gerhart et al. 1989; Maher et al. 1994; Vannucci et al. 1997b; Choi et al. 2001; McAllister et al. 2001; Simpson et al. 2001), and is transported into neural cells via GLUT3 (Nagamatsu et al. 1993; Zeller et al. 1995; Vannucci et al. 1997a). Since linamarin is an analogue of glucose, linamarin could also bind to GLUT, pass through the blood-brain barrier and enter neural cells via GLUT.

3-O-methylglucose, a glucose analogue, also shares GLUT1 across the blood-brain barrier (Dauterive et al. 1996) and is transported into neural cells via GLUT3 (Maher et al. 1996). These facts suggest that a compound carried via GLUT1 also can be transported via GLUT3 and support our hypothesis that linamarin, a glucose analogue, could be carried through blood-brain barrier and be transported into neural cells via GLUT. In the present study, however, when PC12 cells were incubated with glucose alone, cell viability decreased with increase in concentration of glucose $(15-43 \mathrm{~mm})$, probably due to increase in osmolarity by glucose added. When cytochalasin B, an inhibitor of GLUT, was added to the medium containing $15 \mathrm{mM}$-glucose, the toxicity by linamarin significantly reduced. When glucose was added to medium (final concentration was $21 \mathrm{~mm}$ ), toxicity of linamarin to PC12 cells was significantly reduced. These findings strongly suggest that linamarin competes with glucose for GLUT and is transported into the cells via GLUT, whereas cyanide diffusely enters cells.

Transported linamarin does not serve as a substrate or an inhibitor of hexokinase, the key enzyme of glycolytic pathway nor does as a substrate of rhodanese and mercaptopyruvate sulfurtransferase. A greater part of transported linamarin would accumulate in the cytoplasm and cause degenerative change of neural cells as mammalian cells do not contain $\beta$-glucosidase. On the other hand, a smaller part of the linamarin would be transported into lysosome via GLUT (Mancini et al. 1990) and could be hydrolysed by membrane-bound glucosylceramidease, which has $\beta$-glucosidase activity. Cyanohydrin produced would be non-enzymatically hydrolysed to cyanide, which diffuses in cytoplasm and is converted to less toxic thiocyanate by two sulfurtransferases.

Based on the results of the present and previous studies, we propose that pathogenesis of konzo could be complicated; chronic exposure of unmetabolized linamarin causes degenerative change in neural cells; first, chronic exposure of cyanide which is produced from linamarin in the intestine causes decrease in ATP production followed by cell dysfunction; second, chronic exposure of unknown metabolites that are metabolized from linamarin in unknown tissues also cause cell dysfunction (Carlsson et al. 1999). Impairment of detoxification enzyme, rhodanese or mercaptopyruvate sulfurtransferase, cannot be excluded as a possible additional aetiology of konzo.

\section{References}

Barrett MD, Hill DC, Alexander JC \& Zitnak Z (1977) Fate of orally dosed linamarin in the rat. Can J Physiol Pharmacol 55, 134-136.

Bloch R (1973) Inhibition of glucose transport in the human erythrocyte by cytochalasin B. Biochemistry 12, 4779-4801.

Brimer L \& Rosling H (1993) A microdiffusion method with solid state detection of cyanogenic glycosides from cassava in human urine. Food Chem Toxicol 31, 599-603.

Carlsson L, Milingi Juma A, Ronquist G \& Rosling H (1999) Metabolic fates in humans of linamarin in cassava flour ingested as stiff porridge. Food Chem Toxicol 37, 307-312.

Carlsson L, Ronquist G \& Rosling H (1995) A specific and sensitive method for the determination of linamarin in urine. Nat Toxins 3, 378-382.

Choi IY, Lee SP, Kim SG \& Gruetter R (2001) In vivo measurements of brain glucose transport using the reversible Michaelis-Menten model and simultaneous measurements of cerebral blood flow changes during hypoglycemia. J Cereb Blood Flow Metab 21, 653-663.

Dauterive R, Laroux S, Bunn RC, Chaisson A, Sanson T \& Reed BC (1996) C-terminal mutations that alter the turn over number for 3-O-methylglucose transport by GLUT1 and GLUT4. J Biol Chem 271, 11414-11421.

Ellenhorn MJ (1997) Cyanide poisoning. In Ellenhorn's Medical Toxicology: Diagnosis and Treatment of Human Poisoning, 2nd ed., pp. 1476-1482 [MJ Ellenhorn, S Schonwald, G Ordog and J Wasserberger, editors]. Baltimore: A. Waverly Company.

Gerhart DZ, Levasseur RJ, Broderius MA \& Drewes LR (1989) Glucose transporter localization in brain using light and electron immunocytochemistry. J Neurosci Res 22, 464-472.

Harrison W \& Gray R (1972) Stimulaton of yeast hexokinase by catecholamines and related compounds. Arch Biochem Biophys 151, 357-360.

Hernandez T, Lundquist P, Lourdes O, Perez Cristi R, Rodriguez E \& Rosling H (1995) Fate in humans of dietary intake cyanogenic glycosides from root of sweet cassava consumed in Cuba. Nat Toxins 2, 114-117.

Howlett WP (1990) Konzo: A new human disease entity. Acta Hortic 375, 323-329.

Howlett WP, Brubaker GR, Mlingi N \& Rosling H (1990) Konzo an upper motor neurone disease studied in Tanzania. Brain 113, 223-235.

Kamalu BP (1991) The effect of nutritionally balanced cassava (Manihot esculenta crantz) diet on endocrine functioning using the dog as experimental model 1. Pancreas. Brit J Nutr 65, 365-372.

Kamalu BP (1993) Pathological changes in growing dogs fed on a balanced cassava (Manihot escuenta crantz) diet. Brit J Nutr 69, 921-934.

Lancaster PA, Ingram JS, Lim MY \& Coursey DG (1982) Traditional cassava-based foods: Survey of processing techniques. Econ Bot 36, 12-45.

McAllister MS, Krizanac-Bengez L, Macchia F, et al. (2001) Mechanisms of glucose transport at the blood-brain barrier: an in vitro study. Brain Res 904, 20-30. 
Macnamara BP Estimation of toxicity of hydrolytic acid vapors in man. Edgewood Arsenal Technique Report EN-RT-76023, in Records of the US Marine Corps in the Pacific War.

Maduagwu EN (1989) Metabolism of linamarin in rats. Food Chem Toxicol 7, 451-454.

Maher F, Davies-Hill TM \& Simpson IA (1996) Substrate specificity and kinetic parameters of GLUT3 in rat cerebellar granule neurons. Biochem J 315, 1003-1011.

Maher F, Vannucci SJ \& Simpson IA (1994) Glucose transporter protein in brain. FASEB $J \mathbf{8}, 1003-1011$.

Mancini GM, Beerens CE \& Verheijen FW (1990) Glucose transport in lysosomal membrane vesicles. Kinetic demonstration of a carrier for neutral hexoses. J Biol Chem 265, 12380-12387.

Nagahara N, Ito T, Kitamura H \& Nishino T (1998) Tissue and subcellular distribution of mercaptopyruvate sulfurtransferase in the rat: confocal laser fluorescence and immunoelectron microscopic studies combined with biochemical analysis. Histochem Cell Biol 110, 243-250.

Nagahara N, Ito T \& Minami M (1999) Mercaptopyruvate sulfurtransferase as a defense against cyanide toxication: molecular properties and mode of detoxification. Histol Histopathol 14, 1277-1286.

Nagahara N \& Nishino T (1996) Role of amino acid residues in the active site of rat liver mercaptopyruvate sulfurtransferase. J Biol Chem 271, 27395-27401.

Nagahara N, Okazaki T \& Nishino T (1995) Cytosolic mercaptopyruvate Sulfurtransferase is evolutionarily related to mitochondrial rhodanese. J Biol Chem 270, 16230-16235.

Nagamatsu S, Sawa H, Kamada K, Nakamichi Y, Yoshimoto K \& Hoshino T (1993) Neuron-specific glucose transporter (NGST)
CNS distribution of GLUT3 rat glucose transporter (RGT3) in rat central neurons. FEBS Lett 334, 289-295.

Simpson IA, Vannucci SJ, DeJoseph MR \& Hawkins RA (2001) Glucose transporter asymmetries in the bovine blood-brain barrier. J Biol Chem 276, 12725-12729.

Sunderesan S, Nambisan B \& Eqswari Amna CS (1987) Bitterness in cassava in relation to cyanoglucoside content. Indian J Agric Sci 53, 34-40.

Sörbo SH (1953) Crystalline rhodanese, I. Purification and physicochemical examination. Acta Chem Scand 7, 1129-1136.

Stahl B, Wiesinger H \& Hamprecht B (1989) Characterization of sorbitol uptake in rat glial primary cultures. J Neurochem 53, 665-671.

Sylverster DM \& Sander C (1990) Immunohistochemical localization of rhodanese. Histochem J 22, 197-200.

Tylleskar T, Banea M, Bikangi N, Cooke PD, Poulter NH \& Rosling H (1992) Cassava cyanogens and konzo, an upper motoneuron disease found in Africa. Lancet 339, 208-211.

Vannucci SJ, Gibbs EM \& Simpson IA (1997a) Glucose utilization and glucose transporter proteins GLUT3 in brains of diabetic (db/db) mice. Am J Physiol 272, E267-E274.

Vannucci SJ, Maher F \& Simpson IA (1997b) Glucose transporter proteins in the brain: Delivery of glucose to neurons and glia. Glia 21, 2-21.

Winkler WO (1958) Report on method for glucosidal HCN in lima beans. J Assoc Agric Chem 41, 282-287.

Zeller K, Duelli R, Vogel J, Schrock H \& Kuschinsky W (1995) Autoradiographic analysis of the regional distribution of GLUT3 glucose transporters in the rat brain. Brain Res 698, $175-179$. 